\title{
Strong Convergence of a Hybrid Projection Algorithm for Equilibrium Problems, Variational Inequality Problems and Fixed Point Problems in a Banach Space
}

\author{
Wariam Chuayjan ${ }^{1}$ and Sornsak Thianwan ${ }^{2}$ \\ ${ }^{1}$ Department of Mathematics, Faculty of Science, Mahidol University, Bangkok 10400, Thailand \\ ${ }^{2}$ School of Science and Technology, Naresuan Phayao University, Phayao 56000, Thailand \\ Correspondence should be addressed to Sornsak Thianwan, sornsakt@nu.ac.th
}

Received 29 May 2009; Accepted 26 August 2009

Recommended by Simeon Reich

We introduce and study a new hybrid projection algorithm for finding a common element of the set of solutions of an equilibrium problem, the set of common fixed points of relatively quasinonexpansive mappings, and the set of solutions of the variational inequality for an inversestrongly-monotone operator in a Banach space. Under suitable assumptions, we show a strong convergence theorem. Using this result, we obtain some applications in a Banach space. The results obtained in this paper extend and improve the several recent results in this area.

Copyright (C) 2009 W. Chuayjan and S. Thianwan. This is an open access article distributed under the Creative Commons Attribution License, which permits unrestricted use, distribution, and reproduction in any medium, provided the original work is properly cited.

\section{Introduction}

Let $E$ be a real Banach space with norm $\|\cdot\|$ and $E^{*}$ the dual space of $E$. Let $C$ be a nonempty closed and convex subset of $E$, and $A$ a monotone operator of $C$ into $E^{*}$. A mapping $T: C \rightarrow$ $C$ is called nonexpansive if $\|T x-T y\|<\|x-y\|$ for all $x, y \in C$. We denote by $F(T)=\{x \in$ $E: T x=x\}$ the set of fixed points of $T$. The classical variational inequality problem $[1,2]$, denoted by $\operatorname{VI}(C, A)$, is to find $u \in C$ such that

$$
\langle A u, v-u\rangle \geq 0
$$

for all $v \in C$. One can see that the variational inequality problem (1.1) is connected with the convex minimization problem, the complementarity problem, the problem of finding a point $u \in E$ satisfying $0=A u$, and so on. 
Recall that an operator $A$ is called monotone if $\langle A x-A y, x-y\rangle \geq 0$ for all $x, y \in C$. An operator $A$ of $C$ into $E^{*}$ is said to be $\alpha$-inverse-strongly-monotone [3-5] if each $x, y \in C$. We have $\langle A x-A y, x-y\rangle \geq \alpha\|A x-A y\|^{2}$, for a constant $\alpha>0$.

Assume that the following hold:

(C1) $A$ is $\alpha$-inverse-strongly-monotone,

(C2) $\operatorname{VI}(C, A) \neq \emptyset$,

(C3) $\|A y\| \leq\|A y-A u\|$ for all $y \in C$ and $u \in V I(C, A)$.

For finding a solution of the variational inequality problem for an operator $A$ that satisfies conditions (C1)-(C3) in a 2-uniformly convex and uniformly smooth Banach space $E$, Iiduka and Takahashi [6] introduced and studied the following algorithm: $x_{1}=x \in C$, define a sequence $\left\{x_{n}\right\}$ by

$$
x_{n+1}=\Pi_{C} J^{-1}\left(J x_{n}-\lambda_{n} A x_{n}\right)
$$

for every $n=1,2, \ldots$, where $J$ is the duality mapping from $E$ into $E^{*}, \Pi_{C}$ is the generalized projection from $E$ onto $C$, and $\left\{\lambda_{n}\right\}$ is a sequence of positive real numbers. They proved that under certain appropriate conditions imposed on $\left\{\lambda_{n}\right\}$, and $J$ is weakly sequentially continuous, the sequence $\left\{x_{n}\right\}$ generated by (1.2) converges weakly to some element $z$ in $V I(C, A)$, where $z=\lim _{n \rightarrow \infty} \Pi_{V I(C, A)}\left(x_{n}\right)$.

In 2004, Matsushita and Takahashi [7] introduced the following iteration: $x_{0} \in C$ chosen arbitrarily,

$$
x_{n+1}=\Pi_{C} J^{-1}\left(\alpha_{n} J x_{n}+\left(1-\alpha_{n}\right) J T x_{n}\right),
$$

where $\left\{\alpha_{n}\right\}$ is a real sequence in $[0,1], T$ is a relatively nonexpansive mapping, and $\Pi_{C}$ denotes the generalized projection from $E$ onto a closed convex subset $C$ of $E$. They prove that the sequence $\left\{x_{n}\right\}$ generated by (1.3) converges weakly to a fixed point of $T$.

The problem of finding a common element of the set of the variational inequalities for monotone mappings in the framework of Hilbert spaces and Banach spaces has been intensively studied by many authors; see, for instance, [3-5] and the references cited therein.

Let $f$ be a bifunction of $C \times C$ into $\mathbb{R}$, where $\mathbb{R}$ is the set of real numbers. The equilibrium problem for $f: C \times C \rightarrow \mathbb{R}$ is to find $\widehat{x} \in C$ such that

$$
f(\widehat{x}, y) \geq 0
$$

for all $y \in C$. The set of solutions of (1.4) is denoted by $E P(f)$, that is, $E P(f)=\{\widehat{x} \in C$ : $f(\widehat{x}, y) \geq 0$ for all $y \in C\}$. Given a mapping $T: C \rightarrow E^{*}$, let $f(x, y)=\langle T x, y-x\rangle$ for all $x, y \in C$. Then $\widehat{x} \in E P(f)$ if and only if $\langle T \widehat{x}, y-\widehat{x}\rangle \geq 0$ for all $y \in C$, that is, $\widehat{x}$ is a solution of the variational inequality. Many problems in physics, optimization, and economics reduce to finding a solution of (1.4). Equilibrium problems have been studied extensively; see, for instance, $[8,9]$. Combettes and Hirstoaga [8] introduced an iterative scheme for finding the best approximation to the initial data when $E P(f)$ is nonempty and proved a strong convergence theorem. 
For solving the equilibrium problem, let us assume that a bifunction $f$ satisfies the following conditions:

(A1) $f(x, x)=0$ for all $x \in C$;

(A2) $f$ is monotone, that is, $f(x, y)+f(y, x) \leq 0$ for all $x, y \in C$;

(A3) for all $x, y, z \in C$,

$$
\limsup _{t \downarrow 0} f(t z+(1-t) x, y) \leq f(x, y)
$$

(A4) for all $x \in C, f(x, \cdot)$ is convex and lower semicontinuous.

The problem of finding a common element of the set of fixed points and the set of solutions of an equilibrium problem in the framework of Hilbert spaces and Banach spaces has been studied by many authors; see [7, 8, 10-18].

In 2008, Takahashi and Zembayashi [15] introduced the shrinking projection method which is the modification of (1.3) for a relatively nonexpansive mapping. It is given as follows:

$$
\begin{gathered}
x_{0}=x \in C, \quad C_{0}=C, \\
y_{n}=J^{-1}\left(\alpha_{n} J x_{n}+\left(1-\alpha_{n}\right) J T x_{n}\right), \\
u_{n} \in C \text { such that } f\left(u_{n}, y\right)+\frac{1}{r_{n}}\left\langle y-u_{n} J u_{n}-J y_{n}\right\rangle \geq 0, \quad \forall y \in C, \\
C_{n+1}=\left\{z \in C_{n}: \phi\left(z, u_{n}\right) \leq \phi\left(z, x_{n}\right)\right\}, \\
x_{n+1}=\prod_{C_{n+1}} x_{0}
\end{gathered}
$$

for every $n \in \mathbb{N} \cup\{0\}$, where $J$ is the duality mapping on $E,\left\{\alpha_{n}\right\} \subset[0,1]$ satisfying $\liminf _{n \rightarrow \infty} \alpha_{n}\left(1-\alpha_{n}\right)>0$ and $\left\{r_{n}\right\} \subset[s, \infty)$ for some $s>0$. They proved that the sequence $\left\{x_{n}\right\}$ generated by (1.6) converges strongly to $q=\Pi_{F(T) \cap E P(f)} x_{0}$, where $\Pi_{F(T) \cap E P(f)}$ is the generalized projection of $E$ onto $F(T) \cap E P(f)$.

In the same year, Qin et al. [19] extend the iteration process (1.6) from a single relatively nonexpansive mapping to two relatively quasi-nonexpansive mappings: $x_{0} \in$ $E, C_{1}=C$ and $x_{1}=\prod_{C_{1}} x_{0}$,

$$
\begin{gathered}
y_{n}=J^{-1}\left(\alpha_{n} J x_{n}+\beta_{n} J T x_{n}+\gamma_{n} J S x_{n}\right), \\
u_{n} \in C \text { such that } f\left(u_{n}, y\right)+\frac{1}{r_{n}}\left\langle y-u_{n} J u_{n}-J y_{n}\right\rangle \geq 0, \quad \forall y \in C, \\
C_{n+1}=\left\{z \in C_{n}: \phi\left(z, u_{n}\right) \leq \phi\left(z, x_{n}\right)\right\} \\
x_{n+1}=\prod_{C_{n+1}} x_{0}
\end{gathered}
$$


for every $n \in \mathbb{N} \cup\{0\}$. Under appropriate conditions imposed on $\left\{\alpha_{n}\right\},\left\{\beta_{n}\right\},\left\{\gamma_{n}\right\}$, and $\left\{r_{n}\right\}$, they obtain that the sequence $\left\{x_{n}\right\}$ generated by (1.7) converges strongly to $q=$ $\Pi_{F(T) \cap F(S) \cap E P(f)} x_{0}$.

In 2009, Wattanawitoon and Kumam [17] introduced the following iterative scheme which is the modification of (1.6) and (1.7) in a Banach space: $x_{0} \in E, C_{1}=C$, and $x_{1}=\Pi_{C_{1}} x_{0}$,

$$
\begin{gathered}
y_{n}=J^{-1}\left(\delta_{n} J x_{n}+\left(1-\delta_{n}\right) J z_{n}\right), \\
z_{n}=J^{-1}\left(\alpha_{n} J x_{n}+\beta_{n} J T x_{n}+\gamma_{n} J S x_{n}\right), \\
u_{n} \in C \text { such that } f\left(u_{n}, y\right)+\frac{1}{r_{n}}\left\langle y-u_{n}, J u_{n}-J z_{n}\right\rangle \geq 0, \quad \forall y \in C, \\
C_{n+1}=\left\{z \in C_{n}: \phi\left(z, y_{n}\right) \leq \phi\left(z, x_{n}\right)\right\}, \\
x_{n+1}=\prod_{C_{n+1} x_{0}}
\end{gathered}
$$

for finding a common element of the set of solutions of an equilibrium problem and the set of common fixed points of two relatively quasi-nonexpansive mappings in a Banach space. They proved that under certain appropriate conditions imposed on $\left\{\alpha_{n}\right\},\left\{\beta_{n}\right\},\left\{\gamma_{n}\right\},\left\{\delta_{n}\right\}$, and $\left\{r_{n}\right\}$, the sequences $\left\{x_{n}\right\}$ and $\left\{u_{n}\right\}$ generated by (1.8) converge strongly to $q \in F(T) \cap F(S) \cap E P(f)$, where $q=\Pi_{F(T) \cap F(S) \cap E P(f)} x_{0}$.

For finding common elements of the set of the equilibrium problem, the set of the variational inequality problem for an inverse-strongly-monotone operator and the set of common fixed points for relatively quasi-nonexpansive mappings. Cholamjiak [20] introduced an iterative scheme by using the new hybrid method in a Banach space. The scheme is defined as follows: $x_{0} \in E, C_{1}=C$ and $x_{1} \in \Pi_{C_{1}} x_{0 \prime \prime}$

$$
\begin{gathered}
z_{n}=\Pi_{C} J^{-1}\left(J x_{n}-\lambda_{n} A x_{n}\right), \\
y_{n}=J^{-1}\left(\alpha_{n} J x_{n}+\beta_{n} J T x_{n}+\gamma_{n} J S z_{n}\right), \\
u_{n} \in C \text { such that } f\left(u_{n}, y\right)+\frac{1}{r_{n}}\left\langle y-u_{n}, J u_{n}-J y_{n}\right\rangle \geq 0, \quad \forall y \in C, \\
C_{n+1}=\left\{z \in C_{n}: \phi\left(z, u_{n}\right) \leq \phi\left(z, x_{n}\right)\right\}, \\
x_{n+1}=\prod_{C_{n+1}} x_{0}
\end{gathered}
$$

for every $n \in \mathbb{N}$, where $J$ is the duality mapping on $E$ and $\left\{\alpha_{n}\right\},\left\{\beta_{n}\right\}$, and $\left\{\gamma_{n}\right\}$ are sequences in $[0,1]$. He proved that under certain appropriate conditions imposed on $\left\{\alpha_{n}\right\},\left\{\beta_{n}\right\},\left\{\gamma_{n}\right\},\left\{r_{n}\right\}$, and $\left\{\lambda_{n}\right\}$, the sequences $\left\{x_{n}\right\}$ and $\left\{u_{n}\right\}$ generated by (1.9) converge strongly to $q=$ $\Pi_{F(T) \cap F(S) \cap E P(f) \cap V I(C, A)} x_{0}$. 
Motivated by the recent works, we introduce an iterative scheme by a new hybrid method as follows: $x_{0} \in E, C_{1}=C$ and $x_{1}=\Pi_{C_{1}} x_{0}$,

$$
\begin{gathered}
w_{n}=\Pi_{C} J^{-1}\left(J x_{n}-\lambda_{n} A x_{n}\right), \\
y_{n}=J^{-1}\left(\delta_{n} J x_{n}+\left(1-\delta_{n}\right) J w_{n}\right), \\
z_{n}=J^{-1}\left(\alpha_{n} J x_{n}+\beta_{n} J T x_{n}+\gamma_{n} J S y_{n}\right), \\
u_{n} \in C \text { such that } f\left(u_{n}, y\right)+\frac{1}{r_{n}}\left\langle y-u_{n}, J u_{n}-J z_{n}\right\rangle \geq 0, \quad \forall y \in C, \\
C_{n+1}=\left\{z \in C_{n}: \phi\left(z, u_{n}\right) \leq \phi\left(z, x_{n}\right)\right\}, \\
x_{n+1}=\Pi_{C_{n+1}} x_{0}
\end{gathered}
$$

for every $n \in \mathbb{N}$, where $J$ is the duality mapping on $E, \Pi_{C}$ is the generalized projection from $E$ onto a closed convex subset $C$ of $E, f$ is an equilibrium bifunction satisfying (A1)-(A4), $A$ is an operator of $C$ into $E^{*}$ satisfying $(\mathrm{C} 1)-(\mathrm{C} 3), T, S: C \rightarrow C$ are two closed relatively quasinonexpansive mappings, $\left\{\alpha_{n}\right\},\left\{\beta_{n},\left\{\gamma_{n}\right\}\right.$, and $\left\{\delta_{n}\right\}$ are sequences in $[0,1]$ such that $\alpha_{n}+\beta_{n}+\gamma_{n}=$ $1, \limsup _{n \rightarrow \infty} \delta_{n}<1, \liminf _{n \rightarrow \infty} \alpha_{n} \beta_{n}>0$, and $\liminf _{n \rightarrow \infty} \alpha_{n} \gamma_{n}>0,\left\{r_{n}\right\} \subset[s, \infty)$ for some $s>0$ and $\left\{\lambda_{n}\right\} \subset[a, b]$ for some $a, b$ with $0<a<b<c^{2} \alpha / 2$, where $1 / c$ is the 2-uniformly convexity constant of $E$. We prove that the sequences $\left\{x_{n}\right\}$ and $\left\{u_{n}\right\}$ generated by the above iterative scheme converge strongly to $q=\prod_{F(T) \cap F(S) \cap E P(f) \cap V I(C, A)} x_{0}$.

\section{Preliminaries}

In this section, we recall some well know concepts and results.

Let $E$ be a real Banach space with dimension $E \geq 2$. The modulus of $E$ is the function $\delta_{E}:(0,2] \rightarrow[0,1]$ defined by

$$
\delta_{E}(\varepsilon)=\inf \left\{1-\left\|\frac{x+y}{2}\right\|: x, y \in E,\|x\|=\|y\|=1,\|x-y\| \geq \varepsilon\right\}
$$

Banach space $E$ is uniformly convex if and only if $\delta_{E}(\varepsilon)>0$ for all $\varepsilon \in(0,2]$. Let $p$ be a fixed real number with $p \geq 2$. A Banach space $E$ is said to be $p$-uniformly convex if there exists a constant $c>0$ such that $\delta(\varepsilon) \geq c \varepsilon^{p}$ for all $\varepsilon \in[0,2]$; see [21-23] for more details. A Banach space $E$ is said to be smooth if the limit

$$
\lim _{t \rightarrow 0} \frac{\|x+t y\|-\|x\|}{t}
$$

exists for all $x, y \in U$, where $U$ denotes the unit sphere of $E$ (i.e., $U=\{x \in E:\|x\|=1\}$ ). It is also said to be uniformly smooth if the limit (2.2) is attained uniformly for $x, y \in U$. One should note that no Banach space is $p$-uniformly convex for $1<p<2$; see [23]. It is well 
known that a Hilbert space is 2-uniformly convex, uniformly smooth. For each $p>1$, the generalized duality mapping $J_{p}: E \rightarrow 2^{E^{*}}$ is defined by

$$
J_{p}(x)=\left\{x^{*} \in E^{*}:\left\langle x, x^{*}\right\rangle=\|x\|^{p},\left\|x^{*}\right\|=\|x\|^{p-1}\right\}
$$

for all $x \in E$. In particular, $J=J_{2}$ is called the normalized duality mapping. If $E$ is a Hilbert space, then $J=I$, where $I$ is the identity mapping. It is also known that if $E$ is uniformly smooth, then $J$ is uniformly norm-to-norm continuous on each bounded subset of $E$. See $[24,25]$ for more details.

Let $E$ be a smooth, strictly convex, and reflexive Banach space and let $C$ be a nonempty closed convex subset of $E$. We denote by $\phi$ the function defined by

$$
\phi(x, y)=\|x\|^{2}-2\langle x, J y\rangle+\|y\|^{2}
$$

for all $x, y \in E$. Following Alber [26], the generalized projection $\Pi_{C}: E \rightarrow C$ is a map that assigns to an arbitrary point $x \in E$ the minimum point of the functional $\phi(x, y)$, that is, $\Pi_{C} x=\bar{x}$, where $\bar{x}$ is the solution to the minimization problem

$$
\phi(\bar{x}, x)=\inf _{y \in C} \phi(y, x)
$$

The existence and uniqueness of the operator $\Pi_{C}$ follows from the properties of the functional $\phi(x, y)$ and strict monotonicity of the mapping $J$ (see, e.g., [24, 26-29]. In Hilbert space, $\Pi_{C}=$ $P_{C}$. It is obvious from the definition of function $\phi$ that

$$
(\|y\|-\|x\|)^{2} \leq \phi(y, x)=(\|y\|+\|x\|)^{2}
$$

for all $x, y \in E$. If $E$ is a Hilbert space, then $\phi(x, y)=\|x-y\|^{2}$.

If $E$ is a reflexive, strictly convex, and smooth Banach space, then for $x, y \in E, \phi(x, y)=$ 0 if and only if $x=y$. It is sufficient to show that if $\phi(x, y)=0$, then $x=y$. From (2.6), we have $\|x\|=\|y\|$. This implies that $\langle x, J y\rangle=\|x\|^{2}=\|J y\|^{2}$. From the definition of $J$, one has $J x=J y$. Therefore, we have $x=y$; see [24, 28] for more details.

Recall that a point $p$ in a closed convex subset $C$ of $E$ is said to be an asymptotic fixed point of $T$ [30] if $C$ contains a sequence $\left\{x_{n}\right\}$ which converges weakly to $p$ such that $\lim _{n \rightarrow \infty}\left\|x_{n}-T x_{n}\right\|=0$. The set of asymptotic fixed point of $T$ will be denoted by $\widehat{F}(T)$. A mapping $T: C \rightarrow C$ is called relatively nonexpansive [11,31-33] if $T$ satisfies the following conditions:

(1) $F(T) \neq \emptyset$;

(2) $\phi(p, T x) \leq \phi(p, x)$ for all $p \in F(T)$ and $x \in C$;

(3) $\widehat{F}(T)=F(T)$. 33].

The asymptotic behavior of a relatively nonexpansive mapping was studied in [31-

A mapping $T$ is said to be relatively quasi-nonexpansive if $T$ satisfies conditions (1) and (2). It is easy to see that the class of relatively quasi-nonexpansive mappings is more 
general than the class of relatively nonexpansive mappings [11, 31-33] which requires the strong restriction: $F(T)=\widehat{F}(T)$.

We give some examples which are closed relatively quasi-nonexpansive; see [19].

Example 2.1. Let $E$ be a uniformly smooth and strictly convex Banach space and $A \subset E \times E^{*}$ be a maximal monotone mapping such that its zero set $A^{-1} 0 \neq \emptyset$. Then, $J_{r}=(J+r A)^{-1} J$ is a closed relatively quasi-nonexpansive mapping from $E$ onto $D(A)$ and $F\left(J_{r}\right)=A^{-1} 0$.

Example 2.2. Let $\Pi_{C}$ be the generalized projection from a smooth, strictly convex, and reflexive Banach space $E$ onto a nonempty closed convex subset $C$ of $E$. Then, $\Pi_{C}$ is a closed relatively quasi-nonexpansive mapping with $F\left(\Pi_{C}\right)=C$.

An operator $A$ of $C$ into $E^{*}$ is said to be hemicontinuous if for all $x, y \in C$, the mapping $F$ of $[0,1]$ into $E^{*}$ defined by $F(t)=A(t x+(1-t) y)$ is continuous with respect to the weak* topology of $E^{*}$. We define by $N_{C}(v)$ the normal cone for $C$ at a point $v \in C$, that is,

$$
N_{C}(v)=\left\{x^{*} \in E^{*}:\left\langle v-y, x^{*}\right\rangle \geq 0 \forall y \in C\right\} .
$$

Let $C$ be a nonempty, closed convex subset of a Banach space $E$ and $A$ a monotone, hemicontinuous operator of $C$ into $E^{*}$. Let $T_{e} \subset E \times E^{*}$ be an operator defined as follows:

$$
T_{e} v= \begin{cases}A v+N_{C}(v), & v \in C \\ \emptyset, & \text { otherwise }\end{cases}
$$

Then, $T_{e}$ is maximal monotone and $T_{e}^{-1} 0=V I(C, A)$; see [34].

In the sequel, the following lemmas are needed to prove our main results.

Lemma 2.3 ([22,35]). Let $p$ be a given real number with $p \geq 2$ and $E$ a $p$-uniformly convex Banach space. Then, for all $x, y \in E, j_{x} \in J_{p}(x)$ and $j_{y} \in J_{p}(y)$,

$$
\left\langle x-y, j_{x}-j_{y}\right\rangle \geq \frac{c^{p}}{2^{p-2} p}\|x-y\|^{p}
$$

where $J_{p}$ is the generalized duality mapping of $E$ and $1 / c$ is the $p$-uniformly convexity constant of $E$.

Lemma 2.4 ([29]). Let E be a uniformly convex and smooth Banach space and let $\left\{x_{n}\right\}$ and $\left\{y_{n}\right\}$ be two sequences of $E$. If $\phi\left(x_{n}, y_{n}\right) \rightarrow 0$ and either $\left\{x_{n}\right\}$ or $\left\{y_{n}\right\}$ is bounded, then $x_{n}-y_{n} \rightarrow 0$.

Lemma 2.5 ([26]). Let $C$ be a nonempty closed convex subset of a smooth Banach space $E$ and $x \in E$. Then $x_{0}=\Pi_{C} x$ if and only if $\left\langle x_{0}-y, J x-J x_{0}\right\rangle \geq 0$ for all $y \in C$.

Lemma 2.6 ([26]). Let $C$ be a nonempty closed convex subset of a reflexive, strictly convex, and smooth Banach space $E$ and let $x \in E$. Then

$$
\phi\left(y, \Pi_{C} x\right)+\phi\left(\Pi_{C} x, x\right) \leq \phi(y, x), \quad \forall y \in C
$$


Lemma 2.7 ([19]). Let E be a uniformly convex, smooth Banach space, let $C$ be a closed convex subset of $E$, let $T$ be a closed and relatively quasi-nonexpansive mapping from $C$ into itself. Then $F(T)$ is a closed convex subset of $C$.

Lemma 2.8 ([36]). Let E be a uniformly convex Banach space and $B_{r}(0)$ be a closed ball of $E$. Then there exists a continuous strictly increasing convex function $g:[0, \infty) \rightarrow[0, \infty)$ with $g(0)=0$ such that

$$
\|\alpha x+\beta y+\gamma z\|^{2} \leq \alpha\|x\|^{2}+\beta\|y\|^{2}+\gamma\|z\|^{2}-\alpha \beta g(\|x-y\|)
$$

for all $x, y, z \in B_{r}(0)$ and $\alpha, \beta, \gamma \in[0,1]$ with $\alpha+\beta+\gamma=1$.

Lemma 2.9 ([10]). Let $C$ be a closed convex subset of a smooth, strictly convex, and reflexive Banach space $E$, let $f$ be a bifunction from $C \times C$ to $R$ satisfying (A1)-(A4), and let $r>0$ and $x \in E$. Then, there exists $z \in C$ such that

$$
f(z, y)+\frac{1}{r}\langle y-z, J z-J x\rangle \geq 0, \quad \forall y \in C .
$$

Lemma 2.10 ([19]). Let $C$ be a closed convex subset of a uniformly smooth, strictly convex, and reflexive Banach space $E$, and let $f$ be a bifunction from $C \times C$ to $R$ satisfying $(A 1)-(A 4)$. For all $r>0$ and $x \in E$, define a mapping $T_{r}: E \rightarrow C$ as follows:

$$
T_{r} x=\left\{z \in C: f(z, y)+\frac{1}{r}\langle y-z, J z-J x\rangle \geq 0, \forall y \in C\right\} .
$$

Then, the following hold:

(1) $T_{r}$ is single-valued;

(2) $T_{r}$ is a firmly nonexpansive-type mapping [37], that is, for all $x, y \in E$,

$$
\left\langle T_{r} x-T_{r} y, J T_{r} x-J T_{r} y\right\rangle \leq\left\langle T_{r} x-T_{r} y, J x-J y\right\rangle
$$

(3) $F\left(T_{r}\right)=E P(f)$;

(4) $E P(f)$ is closed and convex.

Lemma 2.11 ([16]). Let $C$ be a closed convex subset of a smooth, strictly, and reflexive Banach space $E$, let $f$ be a bifucntion from $C \times C$ to $R$ satisfying (A1)-(A4), let $r>0$. Then, for all $x \in E$ and $q \in F\left(T_{r}\right)$,

$$
\phi\left(q, T_{r} x\right)+\phi\left(T_{r} x, x\right) \leq \phi(q, x)
$$

We make use of the following mapping $V$ studied in Alber [26]:

$$
V\left(x, x^{*}\right)=\|x\|^{2}-2\left\langle x, x^{*}\right\rangle+\left\|x^{*}\right\|^{2}
$$

for all $x \in E$ and $x^{*} \in E^{*}$, that is, $V\left(x, x^{*}\right)=\phi\left(x, J^{-1}\left(x^{*}\right)\right)$. 
Lemma 2.12 ([26]). Let $E$ be a reflexive, strictly convex, smooth Banach space and let $V$ be as in (2.16). Then

$$
V\left(x, x^{*}\right)+2\left\langle J^{-1}\left(x^{*}\right)-x, y^{*}\right\rangle \leq V\left(x, x^{*}+y^{*}\right)
$$

for all $x \in E$ and $x^{*}, y^{*} \in E^{*}$.

\section{Main Results}

In this section, we prove strong convergence theorems by hybrid methods which solves the problem of finding a common element of the set of solutions of an equilibrium problem, the set of common fixed points of relatively quasi-nonexpansive mappings and the set of solutions of the variational inequality of an $\alpha$-inverse-strongly-monotone mapping in a 2uniformly convex, uniformly smooth Banach space.

Theorem 3.1. Let $E$ be a 2-uniformly convex, uniformly smooth Banach space, $C$ a nonempty closed convex subset of $E, f$ a bifunction from $C \times C$ to $\mathbb{R}$ which satisfies (A1)-(A4), $A$ an operator of $C$ into $E^{*}$ satisfying (C1)-(C3), and $T, S$ two closed relatively quasi-nonexpansive mappings from $C$ into itself such that the set $F:=F(T) \cap F(S) \cap E P(f) \cap V I(C, A) \neq \emptyset$. For an initial point $x_{0} \in E$ with $x_{1}=\Pi_{C_{1}} x_{0}$ and $C_{1}=C$, define sequences $\left\{x_{n}\right\}$ and $\left\{u_{n}\right\}$ of $C$ as follows:

$$
\begin{gathered}
w_{n}=\Pi_{C} J^{-1}\left(J x_{n}-\lambda_{n} A x_{n}\right), \\
y_{n}=J^{-1}\left(\delta_{n} J x_{n}+\left(1-\delta_{n}\right) J w_{n}\right), \\
z_{n}=J^{-1}\left(\alpha_{n} J x_{n}+\beta_{n} J T x_{n}+\gamma_{n} J S y_{n}\right), \\
u_{n} \in C \text { such that } f\left(u_{n}, y\right)+\frac{1}{r_{n}}\left\langle y-u_{n} J u_{n}-J z_{n}\right\rangle \geq 0, \quad \forall y \in C, \\
C_{n+1}=\left\{z \in C_{n}: \phi\left(z, u_{n}\right) \leq \phi\left(z, x_{n}\right)\right\}, \\
x_{n+1}=\Pi_{C_{n+1}} x_{0}
\end{gathered}
$$

for every $n \in \mathbb{N}$, where $J$ is the duality mapping on E. Suppose that $\left\{\alpha_{n}\right\},\left\{\beta_{n}\right\},\left\{\gamma_{n}\right\}$, and $\left\{\delta_{n}\right\}$ are sequences in $[0,1]$ satisfying the restrictions:

(B1) $\alpha_{n}+\beta_{n}+\gamma_{n}=1$;

(B2) $\lim \sup _{n \rightarrow \infty} \delta_{n}<1, \liminf _{n \rightarrow \infty} \alpha_{n} \beta_{n}>0$ and $\liminf _{n \rightarrow \infty} \alpha_{n} \gamma_{n}>0$;

(B3) $\left\{r_{n}\right\} \subset[s, \infty)$ for some $s>0$;

(B4) $\left\{\lambda_{n}\right\} \subset[a, b]$ for some $a, b$ with $0<a<b<c^{2} \alpha / 2$, where $1 / c$ is the 2-uniformly convexity constant of $E$.

Then, $\left\{x_{n}\right\}$ and $\left\{u_{n}\right\}$ converge strongly to $q=\Pi_{F} x_{0}$. 
Proof. We divide the proof into eight steps.

Step 1. Show that $\Pi_{F} x_{0}$ and $\Pi_{C_{n+1}} x_{0}$ are well defined.

It is obvious that $\operatorname{VI}(C, A)$ is a closed convex subset of $C$. By Lemma 2.7, we know that $F(T) \cap F(S)$ is closed and convex. From Lemma $2.10(4)$, we also have $E P(f)$ is closed and convex. Hence, $F:=F(T) \cap F(S) \cap E P(f) \cap V I(C, A)$ is a nonempty, closed, and convex subset of $C$; consequently, $\Pi_{F} x_{0}$ is well defined.

Next, we show that $C_{n}$ is closed and convex for all $n \in \mathbb{N}$.

It is obvious that, $C_{1}=C$ is closed and convex. Suppose that $C_{k}$ is closed and convex for some $k \in \mathbb{N}$. For all $z \in C_{k}$, we know that $\phi\left(z, u_{k}\right) \leq \phi\left(z, x_{k}\right)$ is equivalent to

$$
2\left\langle z, J x_{k}-J u_{k}\right\rangle \leq\left\|x_{k}\right\|^{2}-\left\|u_{k}\right\|^{2} .
$$

So, $C_{k+1}$ is closed and convex. Then, for any $n \in \mathbb{N}, C_{n}$ is closed and convex. This implies that $\Pi_{C_{n+1}} x_{0}$ is well defined.

Step 2. We prove by induction that $F \subset C_{n}$ for all $n \in \mathbb{N}$.

Putting $v_{n}=J^{-1}\left(J x_{n}-\lambda_{n} A x_{n}\right)$. First, we observe that $u_{n}=T_{r_{n}} z_{n}$ for all $n \in \mathbb{N}$ and $F \subset C_{1}=C$. Suppose that $F \subset C_{k}$ for some $k \in \mathbb{N}$. Let $u \in F \subset C_{k}$. From Lemmas 2.6 and 2.12, we have

$$
\begin{aligned}
\phi\left(u, w_{k}\right) & =\phi\left(u, \Pi_{C} v_{k}\right) \\
& \leq \phi\left(u, v_{k}\right) \\
& =\phi\left(u, J^{-1}\left(J x_{k}-\lambda_{k} A x_{k}\right)\right) \\
& =V\left(u, J x_{k}-\lambda_{k} A x_{k}\right) \\
& \leq V\left(u,\left(J x_{k}-\lambda_{k} A x_{k}\right)+\lambda_{k} A x_{k}\right)-2\left\langle J^{-1}\left(J x_{k}-\lambda_{k} A x_{k}\right)-u, \lambda_{k} A x_{k}\right\rangle \\
& =V\left(u, J x_{k}\right)-2 \lambda_{k}\left\langle v_{k}-u, A x_{k}\right\rangle \\
& =\phi\left(u, x_{k}\right)-2 \lambda_{k}\left\langle x_{k}-u, A x_{k}\right\rangle+2\left\langle v_{k}-x_{k},-\lambda_{k} A x_{k}\right\rangle .
\end{aligned}
$$

Using (C1) and $u \in V I(C, A)$, we have

$$
\begin{aligned}
-2 \lambda_{k}\left\langle x_{k}-u, A x_{k}\right\rangle & =-2 \lambda_{k}\left\langle x_{k}-u, A x_{k}-A u+A u\right\rangle \\
& =-2 \lambda_{k}\left\langle x_{k}-u, A x_{k}-A u\right\rangle-2 \lambda_{k}\left\langle x_{k}-u, A u\right\rangle \\
& \leq-2 \alpha \lambda_{k}\left\|A x_{k}-A u\right\|^{2} .
\end{aligned}
$$

By using Lemma 2.3 and (C3), we have

$$
\begin{aligned}
2\left\langle v_{k}-x_{k},-\lambda_{k} A x_{k}\right\rangle & =2\left\langle J^{-1}\left(J x_{k}-\lambda_{k} A x_{k}\right)-J^{-1}\left(J x_{k}\right),-\lambda_{k} A x_{k}\right\rangle \\
& \leq 2\left\|J^{-1}\left(J x_{k}-\lambda_{k} A x_{k}\right)-J^{-1}\left(J x_{k}\right)\right\|\left\|\lambda_{k} A x_{k}\right\| \\
& \leq \frac{4}{c^{2}}\left\|J J^{-1}\left(J x_{k}-\lambda_{k} A x_{k}\right)-J J^{-1}\left(J x_{k}\right)\right\|\left\|\lambda_{k} A x_{k}\right\|
\end{aligned}
$$


Abstract and Applied Analysis

$$
\begin{aligned}
& =\frac{4}{c^{2}}\left\|J x_{k}-\lambda_{k} A x_{k}-J x_{k}\right\|\left\|\lambda_{k} A x_{k}\right\| \\
& =\frac{4}{c^{2}} \lambda_{k}^{2}\left\|A x_{k}\right\|^{2} \\
& \leq \frac{4}{c^{2}} \lambda_{k}^{2}\left\|A x_{k}-A u\right\|^{2} .
\end{aligned}
$$

Replacing (3.4) and (3.5) into (3.3) and using (B4), we get

$$
\phi\left(u, w_{k}\right) \leq \phi\left(u, x_{k}\right)+2 a\left(\frac{2}{c^{2}} b-\alpha\right)\left\|A x_{k}-A u\right\|^{2} \leq \phi\left(u, x_{k}\right) .
$$

By the convexity of $\|\cdot\|^{2}$ and (3.6), for each $u \in F \subset C_{k}$, we have

$$
\begin{aligned}
\phi\left(u, y_{k}\right)= & \phi\left(u, J^{-1}\left(\delta_{k} J x_{k}+\left(1-\delta_{k}\right) J w_{k}\right)\right) \\
= & V\left(u, \delta_{k} J x_{k}+\left(1-\delta_{k}\right) J w_{k}\right) \\
= & \|u\|^{2}-2\left\langle u, \delta_{k} J x_{k}+\left(1-\delta_{k}\right) J w_{k}\right\rangle+\left\|\delta_{k} J x_{k}+\left(1-\delta_{k}\right) J w_{k}\right\|^{2} \\
\leq & \|u\|^{2}-2 \delta_{k}\left\langle u, J x_{k}\right\rangle-2\left(1-\delta_{k}\right)\left\langle u, J w_{k}\right\rangle \\
& +\delta_{k}\left\|J x_{k}\right\|^{2}+\left(1-\delta_{k}\right)\left\|J w_{k}\right\|^{2} \\
= & \left(\delta_{k}+\left(1-\delta_{k}\right)\right)\|u\|^{2}-2 \delta_{k}\left\langle u, J x_{k}\right\rangle-2\left(1-\delta_{k}\right)\left\langle u, J w_{k}\right\rangle \\
& +\delta_{k}\left\|J x_{k}\right\|^{2}+\left(1-\delta_{k}\right)\left\|J w_{k}\right\|^{2} \\
= & \delta_{k}\left(\|u\|^{2}-2\left\langle u, J x_{k}\right\rangle+\left\|J x_{k}\right\|^{2}\right)+\left(1-\delta_{k}\right)\left(\|u\|^{2}-2\left\langle u, J w_{k}\right\rangle+\left\|J w_{k}\right\|^{2}\right) \\
= & \delta_{k} \phi\left(u, x_{k}\right)+\left(1-\delta_{k}\right) \phi\left(u, w_{k}\right) \\
\leq & \delta_{k} \phi\left(u, x_{k}\right)+\left(1-\delta_{k}\right) \phi\left(u, x_{k}\right) \\
= & \phi\left(u, x_{k}\right),
\end{aligned}
$$

and so

$$
\begin{aligned}
\phi\left(u, u_{k}\right)= & \phi\left(u, T_{r_{k}} z_{k}\right) \\
\leq & \phi\left(u, z_{k}\right) \\
= & \phi\left(u, J^{-1}\left(\alpha_{k} J x_{k}+\beta_{k} J T x_{k}+\gamma_{k} J S y_{k}\right)\right) \\
= & V\left(u, \alpha_{k} J x_{k}+\beta_{k} J T x_{k}+\gamma_{k} J S y_{k}\right) \\
= & \|u\|^{2}-2 \alpha_{k}\left\langle u, J x_{k}\right\rangle-2 \beta_{k}\left\langle u, J T x_{k}\right\rangle-2 \gamma_{k}\left\langle u, J S y_{k}\right\rangle+\left\|\alpha_{k} J x_{k}+\beta_{k} J T x_{k}+\gamma_{k} J S y_{k}\right\|^{2} \\
\leq & \|u\|^{2}-2 \alpha_{k}\left\langle u, J x_{k}\right\rangle-2 \beta_{k}\left\langle u, J T x_{k}\right\rangle-2 \gamma_{k}\left\langle u, J S y_{k}\right\rangle \\
& +\alpha_{k}\left\|J x_{k}\right\|^{2}+\beta_{k}\left\|J T x_{k}\right\|^{2}+\gamma_{k}\left\|J S y_{k}\right\|^{2}
\end{aligned}
$$




$$
\begin{aligned}
= & \left(\alpha_{k}+\beta_{k}+\gamma_{k}\right)\|u\|^{2}-2 \alpha_{k}\left\langle u, J x_{k}\right\rangle-2 \beta_{k}\left\langle u, J T x_{k}\right\rangle-2 \gamma_{k}\left\langle u, J S y_{k}\right\rangle \\
& +\alpha_{k}\left\|J x_{k}\right\|^{2}+\beta_{k}\left\|J T x_{k}\right\|^{2}+\gamma_{k}\left\|J S y_{k}\right\|^{2} \\
= & \alpha_{k}\left(\|u\|^{2}-2\left\langle u, J x_{k}\right\rangle+\left\|J x_{k}\right\|^{2}\right)+\beta_{k}\left(\|u\|^{2}-2\left\langle u, J T x_{k}\right\rangle+\left\|J T x_{k}\right\|^{2}\right) \\
& +\gamma_{k}\left(\|u\|^{2}-2\left\langle u, J S y_{k}\right\rangle+\left\|J S y_{k}\right\|^{2}\right) \\
= & \alpha_{k} \phi\left(u, x_{k}\right)+\beta_{k} \phi\left(u, T x_{k}\right)+\gamma_{k} \phi\left(u, S y_{k}\right) \\
\leq & \alpha_{k} \phi\left(u, x_{k}\right)+\beta_{k} \phi\left(u, x_{k}\right)+\gamma_{k} \phi\left(u, y_{k}\right) \\
\leq & \alpha_{k} \phi\left(u, x_{k}\right)+\beta_{k} \phi\left(u, x_{k}\right)+\gamma_{k} \phi\left(u, x_{k}\right) \\
= & \left(\alpha_{k}+\beta_{k}+\gamma_{k}\right) \phi\left(u, x_{k}\right) \\
= & \phi\left(u, x_{k}\right) .
\end{aligned}
$$

This shows that $u \in C_{k+1}$ and hence $F \subset C_{k+1}$. This implies that $F \subset C_{n}$ for all $n \in \mathbb{N}$.

Step 3. Show that $\lim _{n \rightarrow \infty} \phi\left(x_{n}, x_{0}\right)$ exists.

From $x_{n}=\Pi_{C_{n}} x_{0}$ and $x_{n+1}=\Pi_{C_{n+1}} x_{0} \in C_{n+1} \subset C_{n}$, we have

$$
\phi\left(x_{n}, x_{0}\right) \leq \phi\left(x_{n+1}, x_{0}\right), \quad \forall n \in \mathbb{N} .
$$

Therefore, $\left\{\phi\left(x_{n}, x_{0}\right)\right\}$ is nondecreasing. From Lemma 2.6, we have

$$
\phi\left(x_{n}, x_{0}\right)=\phi\left(\Pi_{C_{n}} x_{0}, x_{0}\right) \leq \phi\left(u, x_{0}\right)-\phi\left(u, x_{n}\right) \leq \phi\left(u, x_{0}\right) .
$$

Then the sequence $\left\{\phi\left(x_{n}, x_{0}\right)\right\}$ is bounded. It follows that $\lim _{n \rightarrow \infty} \phi\left(x_{n}, x_{0}\right)$ exists.

Step 4. Show that $\left\{x_{n}\right\}$ is a Cauchy sequence in $C$. have

Since $x_{m}=\Pi_{C_{m}} x_{0} \in C_{m} \subset C_{n}$ for any positive integer $m \geq n$, by Lemma 2.6, we also

$$
\begin{aligned}
\phi\left(x_{m}, x_{n}\right) & =\phi\left(x_{m}, \Pi_{C_{n}} x_{0}\right) \\
& \leq \phi\left(x_{m}, x_{0}\right)-\phi\left(\Pi_{C_{n}} x_{0}, x_{0}\right) \\
& =\phi\left(x_{m}, x_{0}\right)-\phi\left(x_{n}, x_{0}\right) .
\end{aligned}
$$

Letting $m, n \rightarrow \infty$ in (3.11), we have $\phi\left(x_{m}, x_{n}\right) \rightarrow 0$. It follows from Lemma 2.4 that $\| x_{m}-$ $x_{n} \| \rightarrow 0$ as $m, n \rightarrow \infty$. Hence, $\left\{x_{n}\right\}$ is a Cauchy sequence. By the completeness of $E$ and the closedness of $C$, one can assume that $x_{n} \rightarrow q \in C$ as $n \rightarrow \infty$. Further, we obtain

$$
\lim _{n \rightarrow \infty} \phi\left(x_{n+1}, x_{n}\right)=0
$$


Since $x_{n+1}=\Pi_{C_{n+1}} x_{0} \in C_{n+1}$, we have

$$
\begin{aligned}
\phi\left(x_{n+1}, u_{n}\right) & \leq \phi\left(x_{n+1}, x_{n}\right) \\
& \longrightarrow 0 \quad(\text { as } n \longrightarrow \infty)
\end{aligned}
$$

Applying Lemma 2.4 to (3.12) and (3.13), we have

$$
\begin{aligned}
\left\|u_{n}-x_{n}\right\| & =\left\|u_{n}-x_{n+1}+x_{n+1}-x_{n}\right\| \\
& \leq\left\|u_{n}-x_{n+1}\right\|+\left\|x_{n+1}-x_{n}\right\| \\
& \longrightarrow 0 \quad(\text { as } n \longrightarrow \infty)
\end{aligned}
$$

This implies that $u_{n} \rightarrow q$ as $n \rightarrow \infty$. Since $J$ is uniformly norm-to-norm continuous on bounded subsets of $E$, we also obtain

$$
\lim _{n \rightarrow \infty}\left\|J u_{n}-J x_{n}\right\|=0
$$

Step 5. Show that $x_{n} \rightarrow q \in F(T) \cap F(S)$.

Let $r=\sup _{n \geq 1}\left\{\left\|x_{n}\right\|,\left\|T x_{n}\right\|,\left\|S w_{n}\right\|\right\}$. From (3.7) and Lemma 2.8, we obtain

$$
\begin{aligned}
\phi\left(u, u_{n}\right)= & \phi\left(u, T_{r_{n}} z_{n}\right) \\
\leq & \phi\left(u, z_{n}\right) \\
= & \phi\left(u, J^{-1}\left(\alpha_{n} J x_{n}+\beta_{n} J T x_{n}+\gamma_{n} J S y_{n}\right)\right) \\
= & V\left(u, \alpha_{n} J x_{n}+\beta_{n} J T x_{n}+\gamma_{n} J S y_{n}\right) \\
= & \|u\|^{2}-2 \alpha_{n}\left\langle u, J x_{n}\right\rangle-2 \beta_{n}\left\langle u, J T x_{n}\right\rangle-2 \gamma_{n}\left\langle u, J S y_{n}\right\rangle \\
& +\left\|\alpha_{n} J x_{n}+\beta_{n} J T x_{n}+\gamma_{n} J S y_{n}\right\|^{2} \\
\leq & \|u\|^{2}-2 \alpha_{n}\left\langle u, J x_{n}\right\rangle-2 \beta_{n}\left\langle u, J T x_{n}\right\rangle-2 \gamma_{n}\left\langle u, J S y_{n}\right\rangle \\
& +\alpha_{n}\left\|J x_{n}\right\|^{2}+\beta_{n}\left\|J T x_{n}\right\|^{2}+\gamma_{n}\left\|J S y_{n}\right\|^{2}-\alpha_{n} \beta_{n} g\left(\left\|J x_{n}-J T x_{n}\right\|\right) \\
= & \left(\alpha_{n}+\beta_{n}+\gamma_{n}\right)\|u\|^{2}-2 \alpha_{n}\left\langle u, J x_{n}\right\rangle-2 \beta_{n}\left\langle u, J T x_{n}\right\rangle-2 \gamma_{n}\left\langle u, J S y_{n}\right\rangle \\
& +\alpha_{n}\left\|J x_{n}\right\|^{2}+\beta_{n}\left\|J T x_{n}\right\|^{2}+\gamma_{n}\left\|J S y_{n}\right\|^{2}-\alpha_{n} \beta_{n} g\left(\left\|J x_{n}-J T x_{n}\right\|\right) \\
= & \alpha_{n} \phi\left(u, x_{n}\right)+\beta_{n} \phi\left(u, T x_{n}\right)+\gamma_{n} \phi\left(u, S y_{n}\right)-\alpha_{n} \beta_{n} g\left(\left\|J x_{n}-J T x_{n}\right\|\right) \\
\leq & \alpha_{n} \phi\left(u, x_{n}\right)+\beta_{n} \phi\left(u, x_{n}\right)+\gamma_{n} \phi\left(u, y_{n}\right)-\alpha_{n} \beta_{n} g\left(\left\|J x_{n}-J T x_{n}\right\|\right) \\
\leq & \alpha_{n} \phi\left(u, x_{n}\right)+\beta_{n} \phi\left(u, x_{n}\right)+\gamma_{n} \phi\left(u, x_{n}\right)-\alpha_{n} \beta_{n} g\left(\left\|J x_{n}-J T x_{n}\right\|\right) \\
= & \phi\left(u, x_{n}\right)-\alpha_{n} \beta_{n} g\left(\left\|J x_{n}-J T x_{n}\right\|\right) .
\end{aligned}
$$


This implies that

$$
\begin{aligned}
\alpha_{n} \beta_{n} g\left(\left\|J x_{n}-J T x_{n}\right\|\right) & \leq \phi\left(u, x_{n}\right)-\phi\left(u, u_{n}\right) \\
& =\left\|x_{n}\right\|^{2}-\left\|u_{n}\right\|^{2}-2\left\langle u, J x_{n}-J u_{n}\right\rangle \\
& \leq\left\|x_{n}-u_{n}\right\|\left(\left\|x_{n}\right\|+\left\|u_{n}\right\|\right)+2\|u\|\left\|J x_{n}-J u_{n}\right\| .
\end{aligned}
$$

It follows from (3.14), (3.15), and (B2) that

$$
\lim _{n \rightarrow \infty} g\left(\left\|J x_{n}-J T x_{n}\right\|\right)=0
$$

Since $g$ is strictly increasing and continuous at 0 with $g(0)=0$, it follows that

$$
\lim _{n \rightarrow \infty}\left\|J x_{n}-J T x_{n}\right\|=0
$$

Since $J$ is uniformly norm-to-norm continuous on bounded sets, so is $J^{-1}$. Then

$$
\lim _{n \rightarrow \infty}\left\|x_{n}-T x_{n}\right\|=\lim _{n \rightarrow \infty}\left\|J^{-1}\left(J x_{n}\right)-J^{-1}\left(J T x_{n}\right)\right\|=0 .
$$

In the same manner, we can show that

$$
\lim _{n \rightarrow \infty}\left\|x_{n}-S y_{n}\right\|=0
$$

In addition, $\phi\left(u, y_{n}\right) \leq \delta_{n} \phi\left(u, x_{n}\right)+\left(1-\delta_{n}\right) \phi\left(u, w_{n}\right)$, using (3.6), we have

$$
\begin{aligned}
\phi\left(u, u_{n}\right) \leq & \alpha_{n} \phi\left(u, x_{n}\right)+\beta_{n} \phi\left(u, x_{n}\right)+\gamma_{n} \phi\left(u, y_{n}\right) \\
\leq & \alpha_{n} \phi\left(u, x_{n}\right)+\beta_{n} \phi\left(u, x_{n}\right)+\gamma_{n}\left(\delta_{n} \phi\left(u, x_{n}\right)+\left(1-\delta_{n}\right) \phi\left(u, w_{n}\right)\right) \\
= & \alpha_{n} \phi\left(u, x_{n}\right)+\beta_{n} \phi\left(u, x_{n}\right)+\gamma_{n} \delta_{n} \phi\left(u, x_{n}\right)+\gamma_{n}\left(1-\delta_{n}\right) \phi\left(u, w_{n}\right) \\
\leq & \alpha_{n} \phi\left(u, x_{n}\right)+\beta_{n} \phi\left(u, x_{n}\right)+\gamma_{n} \delta_{n} \phi\left(u, x_{n}\right) \\
& +\gamma_{n}\left(1-\delta_{n}\right)\left(\phi\left(u, x_{n}\right)+2 a\left(\frac{2}{c^{2}} b-\alpha\right)\left\|A x_{n}-A u\right\|^{2}\right) \\
= & \alpha_{n} \phi\left(u, x_{n}\right)+\beta_{n} \phi\left(u, x_{n}\right)+\gamma_{n} \delta_{n} \phi\left(u, x_{n}\right) \\
& +\gamma_{n}\left(1-\delta_{n}\right) \phi\left(u, x_{n}\right)+\gamma_{n}\left(1-\delta_{n}\right) 2 a\left(\frac{2}{c^{2}} b-\alpha\right)\left\|A x_{n}-A u\right\|^{2} \\
= & \left(\alpha_{n}+\beta_{n}+\gamma_{n}\right) \phi\left(u, x_{n}\right)-\gamma_{n}\left(1-\delta_{n}\right) 2 a\left(\alpha-\frac{2}{c^{2}} b\right)\left\|A x_{n}-A u\right\|^{2} \\
= & \phi\left(u, x_{n}\right)-\gamma_{n}\left(1-\delta_{n}\right) 2 a\left(\alpha-\frac{2}{c^{2}} b\right)\left\|A x_{n}-A u\right\|^{2},
\end{aligned}
$$


which leads to the following:

$$
\gamma_{n}\left(1-\delta_{n}\right) 2 a\left(\alpha-\frac{2}{c^{2}} b\right)\left\|A x_{n}-A u\right\|^{2} \leq \phi\left(u, x_{n}\right)-\phi\left(u, u_{n}\right)
$$

Since $\lim \sup _{n \rightarrow \infty} \delta_{n}<1,0<\liminf _{n \rightarrow \infty} \alpha_{n} \gamma_{n} \leq \liminf _{n \rightarrow \infty} \gamma_{n}$ and from (3.17), we observe

$$
\lim _{n \rightarrow \infty}\left(\phi\left(u, x_{n}\right)-\phi\left(u, u_{n}\right)\right)=0,
$$

which yields that

$$
\lim _{n \rightarrow \infty}\left\|A x_{n}-A u\right\|=0
$$

From Lemmas 2.6 and 2.12, and (3.5), we have

$$
\begin{aligned}
\phi\left(x_{n}, w_{n}\right)=\phi\left(x_{n}, \Pi_{C} v_{n}\right) \leq & \phi\left(x_{n}, v_{n}\right) \\
= & \phi\left(x_{n}, J^{-1}\left(J x_{n}-\lambda_{n} A x_{n}\right)\right) \\
= & V\left(x_{n}, J x_{n}-\lambda_{n} A x_{n}\right) \\
\leq & V\left(x_{n},\left(J x_{n}-\lambda_{n} A x_{n}\right)+\lambda_{n} A x_{n}\right) \\
& -2\left\langle J^{-1}\left(J x_{n}-\lambda_{n} A x_{n}\right)-x_{n}, \lambda_{n} A x_{n}\right\rangle \\
= & \phi\left(x_{n}, x_{n}\right)+2\left\langle v_{n}-x_{n},-\lambda_{n} A x_{n}\right\rangle \\
= & 2\left\langle v_{n}-x_{n},-\lambda_{n} A x_{n}\right\rangle \\
\leq & \frac{4}{c^{2}} b^{2}\left\|A x_{n}-A u\right\|^{2} \\
\longrightarrow & 0 \quad(\text { as } n \longrightarrow \infty) .
\end{aligned}
$$

It follows from Lemma 2.4 and (3.25) that

$$
\lim _{n \rightarrow \infty}\left\|x_{n}-w_{n}\right\|=0
$$

Hence $w_{n} \rightarrow q$ as $n \rightarrow \infty$ and

$$
\lim _{n \rightarrow \infty}\left\|J x_{n}-J w_{n}\right\|=0 .
$$


By using (3.26), we have

$$
\begin{aligned}
\phi\left(x_{n}, y_{n}\right)= & \phi\left(x_{n}, J^{-1}\left(\delta_{n} J x_{n}+\left(1-\delta_{n}\right) J w_{n}\right)\right) \\
= & V\left(u, \delta_{n} J x_{n}+\left(1-\delta_{n}\right) J w_{n}\right) \\
= & \left\|x_{n}\right\|^{2}-2\left\langle x_{n}, \delta_{n} J x_{n}+\left(1-\delta_{n}\right) J w_{n}\right\rangle+\left\|\delta_{n} J x_{n}+\left(1-\delta_{n}\right) J w_{n}\right\|^{2} \\
\leq & \left\|x_{n}\right\|^{2}-2 \delta_{n}\left\langle x_{n}, J x_{n}\right\rangle-2\left(1-\delta_{n}\right)\left\langle x_{n}, J w_{n}\right\rangle \\
& +\delta_{n}\left\|J x_{n}\right\|^{2}+\left(1-\delta_{n}\right)\left\|J w_{n}\right\|^{2} \\
= & \left(\delta_{n}+\left(1-\delta_{n}\right)\right)\left\|x_{n}\right\|^{2}-2 \delta_{n}\left\langle x_{n}, J x_{n}\right\rangle-2\left(1-\delta_{n}\right)\left\langle x_{n}, J w_{n}\right\rangle \\
& +\delta_{n}\left\|J x_{n}\right\|^{2}+\left(1-\delta_{n}\right)\left\|J w_{n}\right\|^{2} \\
= & \delta_{n}\left\|x_{n}\right\|^{2}+\left(1-\delta_{n}\right)\left\|x_{n}\right\|^{2}-2 \delta_{n}\left\langle x_{n}, J x_{n}\right\rangle-2\left(1-\delta_{n}\right)\left\langle x_{n}, J w_{n}\right\rangle \\
& +\delta_{n}\left\|J x_{n}\right\|^{2}+\left(1-\delta_{n}\right)\left\|J w_{n}\right\|^{2} \\
= & \delta_{n} \phi\left(x_{n}, x_{n}\right)+\left(1-\delta_{n}\right) \phi\left(x_{n}, w_{n}\right) \\
\leq & \phi\left(x_{n}, w_{n}\right) \\
\longrightarrow & 0 \quad(\text { as } n \longrightarrow \infty) .
\end{aligned}
$$

Applying Lemma 2.4, we get

$$
\lim _{n \rightarrow \infty}\left\|x_{n}-y_{n}\right\|=0
$$

Hence, $y_{n} \rightarrow q$ as $n \rightarrow \infty$.

In addition,

$$
\begin{aligned}
\left\|S y_{n}-y_{n}\right\| & =\left\|S y_{n}-x_{n}+x_{n}-y_{n}\right\| \\
& \leq\left\|S y_{n}-x_{n}\right\|+\left\|x_{n}-y_{n}\right\|
\end{aligned}
$$

It follows from (3.21), (3.30), and (3.31) that

$$
\lim _{n \rightarrow \infty}\left\|S y_{n}-y_{n}\right\|=0
$$

From (3.20), (3.32) and by the closedness of $T$ and $S$, we get $q \in F(T) \cap F(S)$.

Step 6. Show that $x_{n} \rightarrow q \in E P(f)$.

From (3.16), we have

$$
\phi\left(u, z_{n}\right) \leq \phi\left(u, x_{n}\right)
$$


Note that $u_{n}=T_{r_{n}} z_{n}$. From (3.33) and Lemma 2.11, we have

$$
\begin{aligned}
\phi\left(u_{n}, z_{n}\right)=\phi\left(T_{r_{n}} z_{n}, z_{n}\right) & \leq \phi\left(u, z_{n}\right)-\phi\left(u, T_{r_{n}} z_{n}\right) \\
& \leq \phi\left(u, x_{n}\right)-\phi\left(u, T_{r_{n}} z_{n}\right) \\
& =\phi\left(u, x_{n}\right)-\phi\left(u, u_{n}\right) .
\end{aligned}
$$

Using (3.24), we have $\lim _{n \rightarrow \infty} \phi\left(u_{n}, z_{n}\right)=0$. By Lemma 2.4, we obtain

$$
\lim _{n \rightarrow \infty}\left\|u_{n}-z_{n}\right\|=0
$$

Since $r_{n} \geq s$, we have

$$
\frac{\left\|J u_{n}-J z_{n}\right\|}{r_{n}} \longrightarrow 0 \quad \text { as } n \longrightarrow \infty
$$

From $u_{n}=T_{r_{n}} z_{n}$, we have

$$
f\left(u_{n}, y\right)+\frac{1}{r_{n}}\left\langle y-u_{n}, J u_{n}-J z_{n}\right\rangle \geq 0, \quad \forall y \in C .
$$

By using (A2), we have

$$
\begin{aligned}
\left\|y-u_{n}\right\| \frac{\left\|J u_{n}-J z_{n}\right\|}{r_{n}} & \geq \frac{1}{r_{n}}\left\langle y-u_{n}, J u_{n}-J z_{n}\right\rangle \\
& \geq-f\left(u_{n}, y\right) \geq f\left(y, u_{n}\right), \quad \forall y \in C .
\end{aligned}
$$

From (A4) and $u_{n} \rightarrow q$, we get $f(y, q) \leq 0$ for all $y \in C$. For $t$ with $0<t \leq 1$ and $y \in C$, let $y_{t}=t y+(1-t) q$. Since $y \in C$ and $q \in C$, we have $y_{t} \in C$ and hence $f\left(y_{t}, q\right) \leq 0$. So from (A1), we have $0=f\left(y_{t}, y_{t}\right) \leq t f\left(y_{t}, y\right)+(1-t) f\left(y_{t}, q\right) \leq t f\left(y_{t}, y\right)$. That is, $f\left(y_{t}, y\right) \geq 0$. It follows from (A3) that $f(q, y) \geq 0$ for all $y \in C$ and hence $q \in E P(f)$.

Step 7. Show that $x_{n} \rightarrow q \in V I(C, A)$.

Define $T_{e} \subset E \times E^{*}$ be as in (2.8), which yields that $T_{e}$ is maximal monotone and $T_{e}^{-1} 0=$ $V I(C, A)$. Let $(v, w) \in G\left(T_{e}\right)$. Since $w \in T_{e} v=A v+N_{C}(v)$, we get $w-A v \in N_{C}(v)$. From $w_{n} \in C$, we have

$$
\left\langle v-w_{n}, w-A v\right\rangle \geq 0
$$

On the other hand, from $w_{n}=\Pi_{C} J^{-1}\left(J x_{n}-\lambda_{n} A x_{n}\right)$ and Lemma 2.5, we have $\left\langle v-w_{n}, J w_{n}-\right.$ $\left.\left(J x_{n}-\lambda_{n} A x_{n}\right)\right\rangle \geq 0$, and hence

$$
\left\langle v-w_{n}, \frac{J x_{n}-J w_{n}}{\lambda_{n}}-A x_{n}\right\rangle \leq 0
$$


It follows from (3.39) and (3.40) that

$$
\begin{aligned}
\left\langle v-w_{n}, w\right\rangle \geq & \left\langle v-w_{n}, A v\right\rangle \\
\geq & \left\langle v-w_{n}, A v\right\rangle+\left\langle v-w_{n}, \frac{J x_{n}-J w_{n}}{\lambda_{n}}-A x_{n}\right\rangle \\
= & \left\langle v-w_{n}, A v-A x_{n}\right\rangle+\left\langle v-w_{n}, \frac{J x_{n}-J w_{n}}{\lambda_{n}}\right\rangle \\
= & \left\langle v-w_{n}, A v-A w_{n}\right\rangle+\left\langle v-w_{n}, A w_{n}-A x_{n}\right\rangle \\
& +\left\langle v-w_{n}, \frac{J x_{n}-J w_{n}}{\lambda_{n}}\right\rangle \\
\geq & -\left\|v-w_{n}\right\| \frac{\left\|w_{n}-x_{n}\right\|}{\alpha}-\left\|v-w_{n}\right\| \frac{\left\|J x_{n}-J w_{n}\right\|}{a} \\
\geq & -M\left(\frac{\left\|w_{n}-x_{n}\right\|}{\alpha}+\frac{\left\|J x_{n}-J w_{n}\right\|}{a}\right),
\end{aligned}
$$

where $M=\sup _{n \geq 1}\left\{\left\|v-w_{n}\right\|\right\}$. By taking the limit as $n \rightarrow \infty$ and from (3.27) and (3.28), we obtain $\langle v-q, w\rangle \geq 0$. By the maximality of $T_{e}$, we have $q \in T_{e}^{-1} 0$ and hence $q \in V I(C, A)$. That is, $q \in F$.

Step 8. Show that $q=\Pi_{F} x_{0}$.

From $x_{n}=\Pi_{C_{n}} x_{0}$, we have

$$
\left\langle x_{n}-z, J x_{0}-J x_{n}\right\rangle \geq 0, \quad \forall z \in C_{n}
$$

Since $F \subset C_{n}$, we also have

$$
\left\langle x_{n}-u, J x_{0}-J x_{n}\right\rangle \geq 0, \quad \forall u \in F .
$$

By taking the limit in (3.43), we obtain that

$$
\left\langle q-u, J x_{0}-J q\right\rangle \geq 0, \quad \forall u \in F
$$

By Lemma 2.5, we can conclude that $q=\prod_{F} x_{0}$. From (3.14), we have $\lim _{n \rightarrow \infty}\left\|u_{n}-x_{n}\right\|=0$, and it follows that $\lim _{n \rightarrow \infty}\left\|u_{n}-q\right\|=0$. This completes the proof.

Finally, we prove two strong convergence theorems in a 2-uniformly convex, uniformly smooth Banach space by using Theorem 3.1.

First, we consider the problem of finding a zero point of an inverse-strongly-monotone operator of $E$ into $E^{*}$. Assume that $A$ satisfies the conditions:

(D1) $A$ is $\alpha$-inverse-strongly monotone,

(D2) $A^{-1}(0)=\{u \in E: A u=0\} \neq \emptyset$. 
Theorem 3.2. Let $E$ be a 2-uniformly convex, uniformly smooth Banach space, $f$ a bifunction from $E \times E$ to $\mathbb{R}$ which satisfies (A1)-(A4), A an operator of $E$ into $E^{*}$ satisfying (D1)-(D2), and T, $S$ two closed relatively quasi-nonexpansive mappings from $E$ into itself such that $F:=F(T) \cap F(S) \cap$ $E P(f) \cap A^{-1}(0) \neq \emptyset$. For an initial point $x_{0} \in E$ with $x_{1}=\Pi_{C_{1}} x_{0}$ and $C_{1}=E$, define sequences $\left\{x_{n}\right\}$ and $\left\{u_{n}\right\}$ as follows:

$$
\begin{gathered}
w_{n}=J^{-1}\left(J x_{n}-\lambda_{n} A x_{n}\right), \\
y_{n}=J^{-1}\left(\delta_{n} J x_{n}+\left(1-\delta_{n}\right) J w_{n}\right), \\
z_{n}=J^{-1}\left(\alpha_{n} J x_{n}+\beta_{n} J T x_{n}+\gamma_{n} J S y_{n}\right), \\
u_{n} \in C \text { such that } f\left(u_{n}, y\right)+\frac{1}{r_{n}}\left\langle y-u_{n}, J u_{n}-J z_{n}\right\rangle \geq 0, \quad \forall y \in E, \\
C_{n+1}=\left\{z \in C_{n}: \phi\left(z, u_{n}\right) \leq \phi\left(z, x_{n}\right)\right\}, \\
x_{n+1}=\prod_{C_{n+1}} x_{0}
\end{gathered}
$$

for every $n \in \mathbb{N}$, where $J$ is the duality mapping on E. Suppose that $\left\{\alpha_{n}\right\},\left\{\beta_{n}\right\},\left\{\gamma_{n}\right\}$, and $\left\{\delta_{n}\right\}$ are sequences in $[0,1]$ satisfying conditions (B1)-(B4) of Theorem 3.1.

Then, $\left\{x_{n}\right\}$ and $\left\{u_{n}\right\}$ converge strongly to $q=\Pi_{F} x_{0}$.

Proof. Putting $C=E$ in Theorem 3.1, we have $\Pi_{E}=I$. We also have $V I(E, A)=A^{-1}(0)$ and then condition (C3) of Theorem 3.1 holds for all $y \in E$ and $u \in A^{-1}(0)$. So, we obtain the desired result.

Next, let $K$ be a nonempty closed convex cone in $E$ and $A$ an operator of $K$ into $E^{*}$. We define its polar in $E^{*}$ to be the set

$$
K^{*}=\left\{y^{*} \in E^{*}:\left\langle x, y^{*}\right\rangle \geq 0 \quad \forall x \in K\right\}
$$

Then the element $u \in K$ is called a solution of the complementarity problem if

$$
A u \in K^{*}, \quad\langle u, A u\rangle=0 .
$$

The set of solutions of the complementarity problem is denoted by $C(K, A)$.

Assume that $A$ is an operator satisfying the conditions:

(E1) $A$ is $\alpha$-inverse-strongly-monotone,

(E2) $C(K, A) \neq \emptyset$,

(E3) $\|A y\| \leq\|A y-A u\|$ for all $y \in K$ and $u \in C(K, A)$.

Theorem 3.3. Let E be a 2-uniformly convex, uniformly smooth Banach space, $K$ a nonempty closed convex cone in $E, f$ a bifunction from $K \times K$ to $\mathbb{R}$ which satisfies (A1)-(A4), A an operator of $K$ into $E^{*}$ satisfying (E1)-(E3), and T,S two closed relatively quasi-nonexpansive mappings from $K$ into itself 
such that $F:=F(T) \cap F(S) \cap E P(f) \cap C(K, A) \neq \emptyset$. For an initial point $x_{0} \in E$ with $x_{1}=\Pi_{C_{1}} x_{0}$ and $C_{1}=K$, define sequences $\left\{x_{n}\right\}$ and $\left\{u_{n}\right\}$ as follows:

$$
\begin{gathered}
w_{n}=\Pi_{K} J^{-1}\left(J x_{n}-\lambda_{n} A x_{n}\right), \\
y_{n}=J^{-1}\left(\delta_{n} J x_{n}+\left(1-\delta_{n}\right) J w_{n}\right), \\
z_{n}=J^{-1}\left(\alpha_{n} J x_{n}+\beta_{n} J T x_{n}+\gamma_{n} J S y_{n}\right), \\
u_{n} \in C \text { such that } f\left(u_{n}, y\right)+\frac{1}{r_{n}}\left\langle y-u_{n} J u_{n}-J z_{n}\right\rangle \geq 0, \quad \forall y \in K, \\
C_{n+1}=\left\{z \in C_{n}: \phi\left(z, u_{n}\right) \leq \phi\left(z, x_{n}\right)\right\}, \\
x_{n+1}=\prod_{C_{n+1}} x_{0}
\end{gathered}
$$

for every $n \in \mathbb{N}$, where $J$ is the duality mapping on E. Suppose that $\left\{\alpha_{n}\right\},\left\{\beta_{n}\right\},\left\{\gamma_{n}\right\}$, and $\left\{\delta_{n}\right\}$ are sequences in $[0,1]$ satisfying conditions (B1)-(B4) of Theorem 3.1.

Then, $\left\{x_{n}\right\}$ and $\left\{u_{n}\right\}$ converge strongly to $q=\Pi_{F} x_{0}$.

Proof. From [24, Lemma 7.1.1], we have $V I(K, A)=C(K, A)$. So by Theorem 3.1, we obtain the desired result.

\section{Acknowledgments}

The authors would like to thank the Thailand Research Fund, The Commission on Higher Education, and Naresuan Phayao University, Phayao, Thailand, for financial support during the preparation of this paper.

\section{References}

[1] D. Kinderlehrer and G. Stampacchia, An Introduction to Variational Inequalities and Their Applications, vol. 88 of Pure and Applied Mathematics, Academic Press, New York, NY, USA, 1980.

[2] J.-L. Lions and G. Stampacchia, "Variational inequalities," Communications on Pure and Applied Mathematics, vol. 20, pp. 493-519, 1967.

[3] F. E. Browder and W. V. Petryshyn, "Construction of fixed points of nonlinear mappings in Hilbert space," Journal of Mathematical Analysis and Applications, vol. 20, pp. 197-228, 1967.

[4] H. Iiduka, W. Takahashi, and M. Toyoda, "Approximation of solutions of variational inequalities for monotone mappings," Panamerican Mathematical Journal, vol. 14, no. 2, pp. 49-61, 2004.

[5] F. Liu and M. Z. Nashed, "Regularization of nonlinear ill-posed variational inequalities and convergence rates," Set-Valued Analysis, vol. 6, no. 4, pp. 313-344, 1998.

[6] H. Iiduka and W. Takahashi, "Weak convergence of a projection algorithm for variational inequalities in a Banach space," Journal of Mathematical Analysis and Applications, vol. 339, no. 1, pp. 668-679, 2008.

[7] S. Matsushita and W. Takahashi, "Weak and strong convergence theorems for relatively nonexpansive mappings in Banach spaces," Fixed Point Theory and Applications, vol. 2004, no. 1, pp. 37-47, 2004.

[8] P. L. Combettes and S. A. Hirstoaga, "Equilibrium programming in Hilbert spaces," Journal of Nonlinear and Convex Analysis, vol. 6, no. 1, pp. 117-136, 2005.

[9] S. D. Flåm and A. S. Antipin, "Equilibrium programming using proximal-like algorithms," Mathematical Programming, vol. 78, no. 1, pp. 29-41, 1997.

[10] E. Blum and W. Oettli, "From optimization and variational inequalities to equilibrium problems," The Mathematics Student, vol. 63, no. 1-4, pp. 123-145, 1994. 
[11] S. Matsushita and W. Takahashi, "A strong convergence theorem for relatively nonexpansive mappings in a Banach space," Journal of Approximation Theory, vol. 134, no. 2, pp. 257-266, 2005.

[12] S. Plubtieng and K. Ungchittrakool, "Strong convergence theorems for a common fixed point of two relatively nonexpansive mappings in a Banach space," Journal of Approximation Theory, vol. 149, no. 2, pp. 103-115, 2007.

[13] A. Tada and W. Takahashi, "Weak and strong convergence theorems for a nonexpansive mapping and an equilibrium problem," Journal of Optimization Theory and Applications, vol. 133, no. 3, pp. 359-370, 2007.

[14] S. Takahashi and W. Takahashi, "Strong convergence theorem for a generalized equilibrium problem and a nonexpansive mapping in a Hilbert space," Nonlinear Analysis: Theory, Methods E Applications, vol. 69, no. 3, pp. 1025-1033, 2008.

[15] W. Takahashi and K. Zembayashi, "Strong convergence theorem by a new hybrid method for equilibrium problems and relatively nonexpansive mappings," Fixed Point Theory and Applications, vol. 2008, Article ID 528476, 11 pages, 2008.

[16] W. Takahashi and K. Zembayashi, "Strong and weak convergence theorems for equilibrium problems and relatively nonexpansive mappings in Banach spaces," Nonlinear Analysis: Theory, Methods $\mathcal{E}$ Applications, vol. 70, no. 1, pp. 45-57, 2009.

[17] K. Wattanawitoon and P. Kumam, "Strong convergence theorems by a new hybrid projection algorithm for fixed point problems and equilibrium problems of two relatively quasi-nonexpansive mappings," Nonlinear Analysis: Hybrid Systems, vol. 3, no. 1, pp. 11-20, 2009.

[18] Y. Yao, M. A. Noor, and Y.-C. Liou, "On iterative methods for equilibrium problems," Nonlinear Analysis: Theory, Methods \& Applications, vol. 70, no. 1, pp. 497-509, 2009.

[19] X. Qin, Y. J. Cho, and S. M. Kang, "Convergence theorems of common elements for equilibrium problems and fixed point problems in Banach spaces," Journal of Computational and Applied Mathematics, vol. 225, no. 1, pp. 20-30, 2009.

[20] P. Cholamjiak, "A hybrid iterative scheme for equilibrium problems, variational inequality problems, and fixed point problems in Banach spaces," Fixed Point Theory and Applications, vol. 2009, Article ID 719360, 18 pages, 2009.

[21] K. Ball, E. A. Carlen, and E. H. Lieb, "Sharp uniform convexity and smoothness inequalities for trace norms," Inventiones Mathematicae, vol. 115, no. 3, pp. 463-482, 1994.

[22] B. Beauzamy, Introduction to Banach Spaces and Their Geometry, vol. 68 of North-Holland Mathematics Studies, North-Holland, Amsterdam, The Netherlands, 2nd edition, 1985.

[23] Y. Takahashi, K. Hashimoto, and M. Kato, "On sharp uniform convexity, smoothness, and strong type, cotype inequalities," Journal of Nonlinear and Convex Analysis, vol. 3, no. 2, pp. 267-281, 2002.

[24] W. Takahashi, Takahashi, Nonlinear Functional Analysis: Fixed Point Theory and Its Application, Yokohama, Yokohama, Japan, 2000.

[25] W. Takahashi, Convex Analysis and Approximation of Fixed Points, vol. 2, Yokohama, Yokohama, Japan, 2000.

[26] Ya. I. Alber, "Metric and generalized projection operators in Banach spaces: properties and applications," in Theory and Applications of Nonlinear Operators of Accretive and Monotone Type, A. G. Kartsatos, Ed., vol. 178 of Lecture Notes in Pure and Applied Mathematics, pp. 15-50, Marcel Dekker, New York, NY, USA, 1996.

[27] Ya. I. Alber and S. Reich, "An iterative method for solving a class of nonlinear operator equations in Banach spaces," Panamerican Mathematical Journal, vol. 4, no. 2, pp. 39-54, 1994.

[28] I. Cioranescu, Geometry of Banach Spaces, Duality Mappings and Nonlinear Problems, vol. 62 of Mathematics and Its Applications, Kluwer Academic Publishers, Dordrecht, The Netherlands, 1990.

[29] S. Kamimura and W. Takahashi, "Strong convergence of a proximal-type algorithm in a Banach space," SIAM Journal on Optimization, vol. 13, no. 3, pp. 938-945, 2002.

[30] S. Reich, "A weak convergence theorem for the alternating method with Bregman distances," in Theory and Applications of Nonlinear Operators of Accretive and Monotone Type, A. G. Kartsatos, Ed., vol. 178 of Lecture Notes in Pure and Applied Mathematics, pp. 313-318, Marcel Dekker, New York, NY, USA, 1996.

[31] D. Butnariu, S. Reich, and A. J. Zaslavski, "Asymptotic behavior of relatively nonexpansive operators in Banach spaces," Journal of Applied Analysis, vol. 7, no. 2, pp. 151-174, 2001.

[32] D. Butnariu, S. Reich, and A. J. Zaslavski, "Weak convergence of orbits of nonlinear operators in reflexive Banach spaces," Numerical Functional Analysis and Optimization, vol. 24, no. 5-6, pp. 489-508, 2003. 
[33] Y. Censor and S. Reich, "Iterations of paracontractions and firmly nonexpansive operators with applications to feasibility and optimization," Optimization, vol. 37, no. 4, pp. 323-339, 1996.

[34] R. T. Rockafellar, "On the maximality of sums of nonlinear monotone operators," Transactions of the American Mathematical Society, vol. 149, pp. 75-88, 1970.

[35] C. Zălinescu, "On uniformly convex functions," Journal of Mathematical Analysis and Applications, vol. 95, no. 2, pp. 344-374, 1983.

[36] Y. J. Cho, H. Zhou, and G. Guo, "Weak and strong convergence theorems for three-step iterations with errors for asymptotically nonexpansive mappings," Computers \& Mathematics with Applications, vol. 47, no. 4-5, pp. 707-717, 2004.

[37] F. Kohsaka and W. Takahashi, "Existence and approximation of fixed points of firmly nonexpansivetype mappings in Banach spaces," SIAM Journal on Optimization, vol. 19, no. 2, pp. 824-835, 2008. 


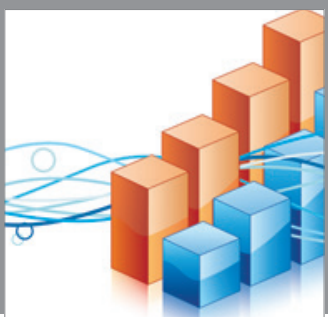

Advances in

Operations Research

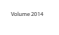

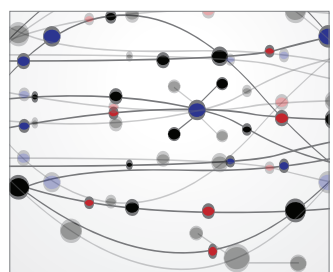

\section{The Scientific} World Journal
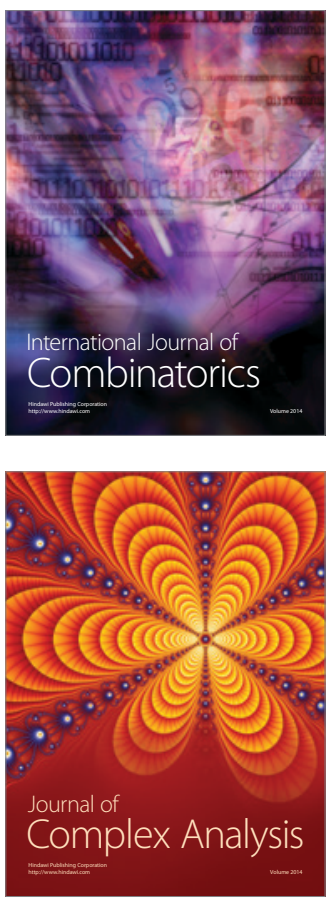

International Journal of

Mathematics and

Mathematical

Sciences
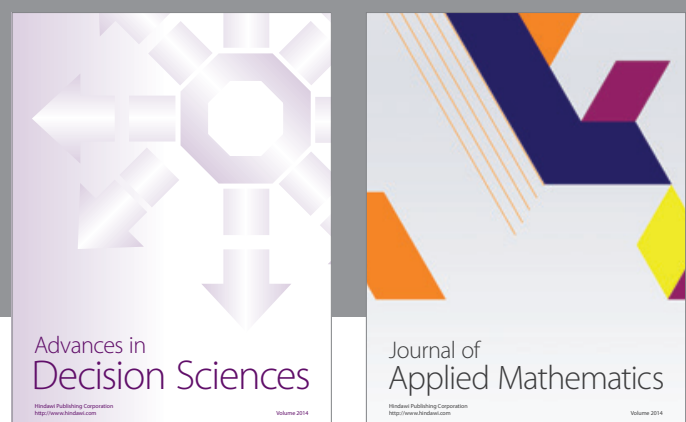

Journal of

Applied Mathematics
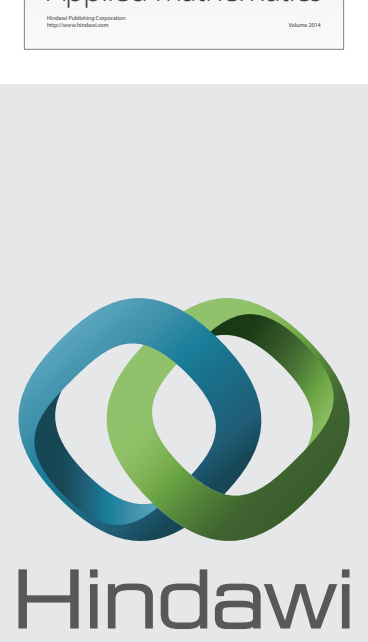

Submit your manuscripts at http://www.hindawi.com
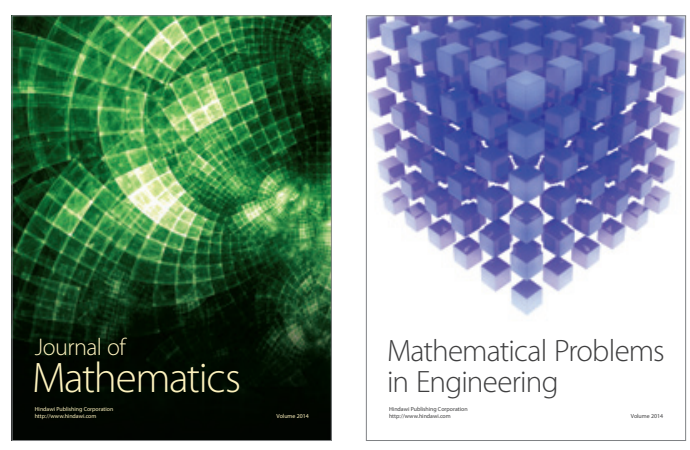

Mathematical Problems in Engineering
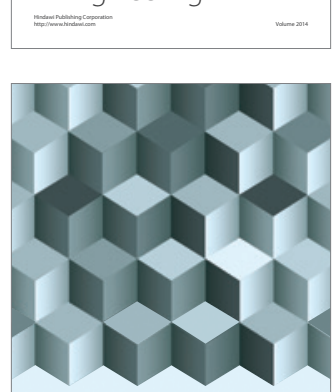

Journal of

Function Spaces
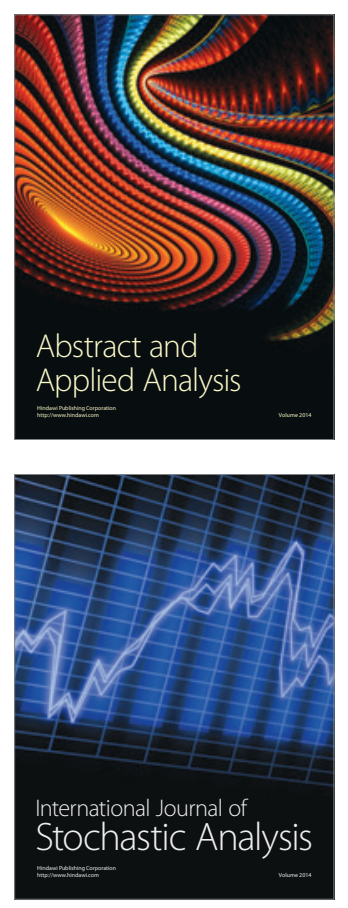

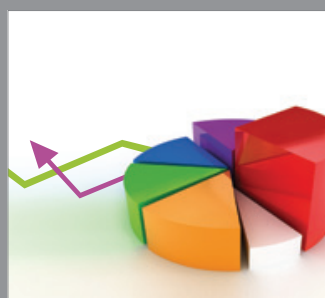

ournal of

Probability and Statistics

Promensencen
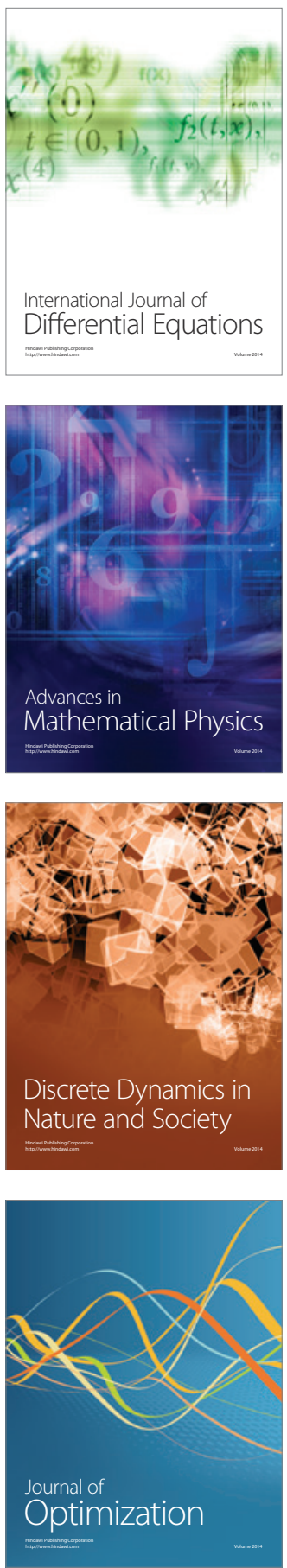